\title{
Malaria Outbreak Investigation and Response in Bolosso Sore Wereda, Welayta Zone, SNNPR, Ethiopia, 2019
}

Awol Mohammed Dawud ( $\nabla$ awol.mod@gmail.com )

Ethiopian Public Health Institute https://orcid.org/0000-0003-1509-9763

Hailemichael Bizuneh

St Paul's Hospital Millennium Medical College

Zewdu Assefa

Ethiopian Public Health Institute

\section{Research}

Keywords: Malaria, outbreak, Boloso Sore wereda, risk factor.

Posted Date: August 6th, 2021

DOl: https://doi.org/10.21203/rs.3.rs-705729/v1

License: (1) This work is licensed under a Creative Commons Attribution 4.0 International License.

Read Full License 


\section{Abstract}

Background; Malaria is caused by one or more of the five species of plasmodium species that can infect by the bite of female Anopheles. In Ethiopia, about $68 \%$ of the total population resides in areas with high malaria risk and 2,174,707 cases and 662 deaths due to malaria were reported in 2014-2015 with case fatality rate of $0.03 \%$. The outbreak was reported on April 22/2019 (WHO week 17) then we investigate the outbreak to describe the magnitude of morbidity and mortality due to malaria outbreak, identify the etiologic agent and investigate factors associated with an occurrence of malaria outbreak.

Methods; we conducted case control study in Bolosso Sore woreda. We used outbreak investigation questionnaire to asses' risk factor for both cases and controls of patients. We collected 75 cases and 150 controls by face to face interview by administered questionnaire. We analysed the data with Epi Info.Version7.2.0.1 and SPSS.V 23 and the statistical we used 95\% $\mathrm{Cl}$.

Result; the overall attack rate of the woreda was 36.4 per 1000. From the cases Males are slightly more affected than females (38: 37). The most affected age group is $>15$ years, 54 (72\%) followed by $5-14$, $17(22.7 \%)$. Plasmodium falcifarem is the highest proportion of malaria in the wereda. Having impregnated treated net have no problem but impregnated treated net who have used sometimes (AOR $10.214 ; 95 \% \mathrm{Cl}$ ) was identified as a risk factor for malaria or more likely affected by malaria ten times each respectively than those impregnated treated net used always.

Conclusion; Presence of intermittent rivers nearest to the community, open deep well near to their home and usage of impregnated treated net (those impregnated treated net use sometimes and never use impregnated treated net) were risk factors for onset/occurrence of the outbreak of malaria. We recommend all malarias area insecticide treated bed net should be distributed for all households according to their family member. Beside this, utilization of bed net should be monitored and optimized.

\section{Background}

Malaria is caused by one or more of the five species of plasmodium species that can infect by the bite of female Anopheles [1]. Humans are infected by malaria through the bite of a female Anopheles mosquito. Once in the human body the parasites multiply rapidly, first in the liver, followed in the blood.

Globally, malaria affects the lives of 247 million people and kills close to a million each year $90 \%$ of which are among Africans [2]. Approximately 53 million Ethiopians (63\% of the population) live in malaria risk areas. Of these, 33 million almost $40 \%$ of the total population are in endemic areas, and nearly one quarter of Ethiopians reside in endemic prone areas. Ethiopia is among the few countries with unstable malaria transmission and also is one of the most malaria epidemic-prone countries in Africa.

Due to Ethiopia's complex topography and seasonal rainfall support largely seasonal short-term transmission, malaria is generally unstable that put the population non-immune [3]. Recurrent outbreaks and epidemics are associated with cyclical climatic variations that lead to increased vector survival in the 
country. Generally, malaria cases are peaked after two rainy season (March - May and July-September). The country has experienced the worst malaria epidemics in 1958 with three million cases and 150,000 deaths [4].

Other triggering factors like unusual local weather phenomena and activities resulting in environmental modification that increase vector population, increased vulnerability of population from famine and malnutrition, Interruptions of anti-malarial measures which have kept malaria under control. However, there could be outbreak in high transmission areas if there is deterioration of health system, interruption of anti-malarial measures or migration of non-immune individuals [5].

Malaria outbreak occurs within the first five years this is the highest one in the district. Moreover, prevention programs and timely investigation of outbreaks by using surveillance data are the main purposes of Integrated Disease Surveillance. The purpose of this study is to verify the existence of the outbreak, identify gaps and risk factors contributed to the existence of the outbreak and provide proper public health intervention for the outbreak in Bolosso Sore woreda.

\section{Methodology}

\section{Study Area}

Boloso Sore is one of the woredas in the SNNPR of Ethiopia. Bolosso Sore located from the North and East latitude: $7^{\circ} 04^{\prime} 60.00^{\prime \prime} \mathrm{N}$ longitude: $37^{\circ} 39^{\prime} 59.99^{\prime \prime} \mathrm{E}$ respectively. It has 32 kebeles and 8 health centers. Some kebelese of the wereda are high malarias i.e. 17 kebeles of the wereda are malarias area and the outbreak occur in all cluster but differ in magnitude. The climate and the topography of the area are favourable for malaria insect breeding.

\section{Study design and Period}

Conducted descriptive and unmatched case- control study for analytical part of the study on the active patients. And it conducted from April 22/2019-August 28/2019.

\section{Source population and Study Subject}

The source population are peoples living in Bolosso Sore woreda of Welayta Zone at risk of malaria. And the specific study subjects for cases were febrile patients who are positive for malaria parasites by the rapid diagnostic tests or microscope. Study subjects for control were non febrile apparently healthy person who is living in the same village with the active case patient from April 22-August 28/2019.

\section{Sample size determination}

The sample size was calculated based on power requirements at both cases and control. It is done by using two by two tables by adjusting two sided confidence level at $95 \%$, power (percentage chance of detecting) was $80 \%$, ratio of control to case at 2, hypothetical proportion of controls with exposure at $50 \%$ and least extreme Odds Ratio to be detected was OR of 2.3 of Gemechu malaria outbreak 
investigation (calculated from Epiinfo7.2.0.1) [6].The total number of people included in the study were 225 individuals, 75 were cases and 150 were controls. And All Case subjects were active cases and controls were selected for each case in 1:2 ratio bases from the same Community family or neighbour from controls were at the same time.

\section{Sampling procedure and Sampling Technique}

Health centers were selected for cases- control study and community diagnosis based on the high weekly Malaria case report i.e. purposely. We used a structured and semi structured questionnaire to conduct interview from cases and controls on the risk factors. And also interviewed the health office and health cluster (HCs) PHEM officers on control and prevention program in the woreda. The sampling technique was those patients who came to the health cetnter and became malaria positive and selected randomly from the list. That means we use simple random sampling technique.

\section{Laboratory Method}

Rapid Diagnostic Test and microscope were used in the health centre. Health extension workers also used RDT to identify confirmed malaria cases at health post and Community level during outbreak investigation case searching.

\section{Environmental Assessment}

Data was collected on the presence of potential mosquito breeding sites. Selected case-patients and controls were interviewed about presence of mosquito breeding sites in their compound and near to home. In addition, availability of uncovered plastic water container, old tires, stagnant water and broken glasses in the home or outside the home were also critically assessed.

\section{Data Analysis}

Quantitative data was collected using face to face interviewing by administered questionnaire that addressed socio-demographic characteristics, clinical manifestation, potential exposures (risk factor), review of weekly integrated disease surveillance and response at different level (Wereda Health office), visited of the affected village and interview community members. We entered data by using Epi Info version 7.2.0.1 and we use SPSS to analyse associated factors. The significance of risk factors for the outbreak was determined through logistic regression of bivariate and multivariate analysis by calculating Odds Ratio and 95\% Confidence Interval. A p-value of less than 0.05 was considered significant.

\section{Results}

There was a total of 225 samples of a malaria cases and throughout the outbreak there were no death occur. From the total of malaria confirmed cases the most affected age group was > 15 years, 54 (72\%) followed by $5-14,17(22.7 \%)$. From the total $50 \%$ of them were $>15$ years of age. Males $38(51 \%)$ were slightly more affected than females. And nobody refused to be interviewed. The other socio demographic parts are expressed below. 


\section{Laboratory}

From April 15 to August 25, 2019 a total of 4,380 blood smear positive (confirmed positive) of Bolosso Sore Woreda. Of which, 3,281 (75\%) were positive for P. Falciparum, 1,100 (25\%) were P. Vivax. This is from a weekly report of the zone and the wereda.

\section{Descriptive Epidemiology}

\section{Description of the overall epidemic situation}

Five years woreda data was shows that there was no outbreak within those five years. Bolosso Sore woreda Weekly malaria case passed the threshold level on WHO Week 18 (from April 22) and the health office has detected the outbreak on Week 18 based on the established threshold and writing letters about the outbreak to health centers for alerting the outbreak then similarly to Zonal health department. And the wereda was actively worked for the response of the outbreak and they controlled it. There was no death reported. At woreda and Zonal level no investigation was done until the national team conduct investigation.

\section{Description of cases by Time}

The number of cases passed the threshold level in epi. Week of $18 / 2019$ continued consistently increasing and reached peak on week (20) and then with sharp decrease on each week and steadily decreasing from week 29 up to Week 35 and it was decreased and controlled. The outbreak started on Week 18 of the epidemiologic week by crossing the threshold and reached peak on week 20. The intervention was started lately by mass treatment and ten kebeles of focal points or areas Profoxer/IRS sprayed and stagnant water were larvicide by Abet chemical.

\section{Epi curve of the Outbreak}

The outbreak was started from week 18, peaks at week 20 and then stopped or controlled from week 34 till this investigation done.

\section{Clinical features of cases}

A total of 75 active cases from Gurmo kosha H/C cluster, Achura H/C cluster, Gara Gudo H/C cluster, Woybo H/C cluster, Legama H/C cluster, D/Salata H/C cluster and selected kebelese of each cluster of Bolosso Sore woreda enrolled in the study from the bigining of the outbreak April 2019 till week 35. This is only the cases that interviewed by questionnaire.

The most frequently manifested clinical feature among the cases were fever, shivering, vomiting, headache, Anorexia, rigor and back pain 73(97\%), 51(68\%), 48(64\%), 70(93\%), 60(80\%), 58(77\%) and $59(79 \%)$ respectively. There were complications or severe malaria happened according to the sign and symptoms they answered. Those were altered consciousness $1 \%$, not able to fed or drunk $5 \%$, severe dehydration $6 \%$, persistent fever $9 \%$, frequent vomiting $7 \%$ and unable to sit or stand up $4 \%$. 


\section{Description of Cases by person}

Bolosso Sore Woreda has a total population under surveillance of 211,145 out of this 120,252 are at risk of malaria. The overall attack rate (AR) for the woreda was 36.4/1000. From the cases Males are more affected than females (38: 37). The most affected age group is $>15$ years, 54 (72\%) followed by $5-14$, $17(22.7 \%)$. The educational status of the study participants were illiterate (7) and 31 attended school at primary level. Regarding Marital status of study participants, $52 \%$ were married, $16 \%$ NA or underage and $32 \%$ single.

\section{Description of cases by place}

Most active cases were from Gurmo Koysha cluster. The wereda has 8 clusters in which in each cluster has three to five kebeles. Embecho and Afama Bancha clusters were not included in case controls study because of their topography difficulty and the number of cases somehow small. We interviewed $75 \mathrm{a}$ case from six clusters (G/koysha H/C, Gara Gudo H/C, Achura H/C, D/salata H/C, Legama H/C and Woybo $\mathrm{H} / \mathrm{C}$ ). The investigation team treated a total of serologically confirmed (positive) 75 cases.

\section{Analytical Epidemiology (Case -Control)}

A total of 75 malaria cases and 150 apparently healthy controls were included into this analysis. We assessed possible risk factors that contribute to contracting malaria. In another bi-varate analysis who staying overnight $43 \%$ (P-value 0.028 ) is less likely affected by malaria than those not staying overnight. ITN who have used sometimes (COR 2.343) and those have ITN and they never use ITN (COR 2.248) were identified as a risk factor for malaria or more likely affected by malaria two times each respectively than those used ITN always.

In multi variate logistic regression some times and never ITN usage (AOR 10.214, $95 \%$ Cl1.163-89.725 and AOR $32.098,95 \% \mathrm{Cl} 3.570-288.133$ respectively ) were found to be independent risk factors of malaria infection in the study area or they were the highest risk factors. In general, those who have an $A O R<1$ they were found to be preventive or had less risk for malaria infection (Table 6). 
Table 1

; Socio demographic Characteristics of Bolosso Sore Woreda,Wolayta zone, SNNPR, September,2019

\begin{tabular}{|c|c|c|c|c|c|c|c|}
\hline SNO. & Variables & & Case & Control & AR & Total & $\%$ \\
\hline \multirow[t]{5}{*}{1} & \multirow[t]{5}{*}{ Occupation } & Employed & 2 & 23 & $3 \%$ & 25 & $11 \%$ \\
\hline & & Unemployed & 5 & 8 & $7 \%$ & 13 & $6 \%$ \\
\hline & & Student & 31 & 38 & $41 \%$ & 69 & $30.7 \%$ \\
\hline & & Pastoralist & 5 & 1 & $5 \%$ & 6 & $2.7 \%$ \\
\hline & & Farmer & 32 & 81 & $44 \%$ & 113 & $50.2 \%$ \\
\hline \multirow[t]{2}{*}{2} & \multirow[t]{2}{*}{ Total family Size } & 2-5 members & 30 & 40 & $40 \%$ & 70 & $31 \%$ \\
\hline & & $>5$ members & 46 & 109 & $61 \%$ & 155 & $69 \%$ \\
\hline \multirow[t]{3}{*}{3} & \multirow[t]{3}{*}{ Marital Status } & Married & 39 & 80 & $52 \%$ & 119 & $53 \%$ \\
\hline & & Single & 24 & 51 & $32 \%$ & 75 & $33 \%$ \\
\hline & & NA & 12 & 19 & $16 \%$ & 31 & $14 \%$ \\
\hline \multirow[t]{6}{*}{4} & \multirow[t]{6}{*}{ Education } & Ilitrate & 7 & 24 & $9 \%$ & 31 & $14 \%$ \\
\hline & & Primary & 31 & 58 & $41 \%$ & 89 & $40 \%$ \\
\hline & & Secondary & 16 & 23 & $21 \%$ & 39 & $17 \%$ \\
\hline & & Tertiary & 4 & 11 & $5 \%$ & 15 & $7 \%$ \\
\hline & & Non-formal & 8 & 21 & $11 \%$ & 29 & $13 \%$ \\
\hline & & NA & 5 & 17 & $7 \%$ & 22 & $10 \%$ \\
\hline
\end{tabular}

Table 2

; distributions of Total malaria positivity by age group and sex in Bolosso Sore Wereda, Wolayta Zone, August 2019 (from the interview of cases)

\begin{tabular}{|lllll|}
\hline Characteristics & Catagory & Total Malaria & PF & PV \\
\hline Sex & Male & 38 & 35 & 3 \\
\cline { 2 - 5 } & Female & 37 & 27 & 10 \\
\cline { 2 - 5 } & Total & 75 & 62 & 13 \\
\hline \multirow{3}{*}{ Age } & $<5$ years & 5 & 5 & 0 \\
\cline { 2 - 5 } & $5-14$ years & 17 & 15 & 2 \\
\hline$>15$ years & 53 & 42 & 13 \\
\hline
\end{tabular}


Table 3

Distribution of malaria cases by cluster and AR in Bolosso Sore Wereda, Wolayta zone, SNNRP, April 21 to August 25, 2019 (from WHO epi week 17-35)

\begin{tabular}{|lllllll|}
\hline SNO & Name of H/C & $\begin{array}{l}\text { Total } \\
\text { population }\end{array}$ & $\begin{array}{l}\text { Number of } \\
\text { PF }\end{array}$ & $\begin{array}{l}\text { Number of } \\
\text { PV }\end{array}$ & $\begin{array}{l}\text { Total number of } \\
\text { cases }\end{array}$ & $\begin{array}{l}\text { AR per } \\
1000\end{array}$ \\
\hline 01 & G/koysha H/C & 23,225 & 785 & 257 & 1,042 & $45 \%$ \\
\hline 02 & Gara gudo H/C & 37,106 & 378 & 63 & 441 & $11.9 \%$ \\
\hline 03 & Achura H/C & 17,309 & 131 & 78 & 209 & $12 \%$ \\
\hline 04 & $\begin{array}{l}\text { Dangra Salata } \\
\text { H/C }\end{array}$ & 19,473 & 741 & 157 & 898 & $46.1 \%$ \\
\hline 05 & Legama H/C & 20,470 & 524 & 116 & 640 & $31.3 \%$ \\
\hline 06 & Woybo H/C & 25,381 & 111 & 41 & 152 & $6 \%$ \\
\hline 07 & Embecho H/C & 33,883 & 232 & 276 & 508 & $15 \%$ \\
\hline 08 & $\begin{array}{l}\text { Afama Bancha } \\
\text { H/C }\end{array}$ & 32,589 & 110 & 119 & 229 & $7 \%$ \\
\hline
\end{tabular}


Table 4

; Socio-demographic Bi-varate Analysis of Bolosso Sore Wereda, SNNPR, 2019

\begin{tabular}{|c|c|c|c|c|c|c|c|c|}
\hline \multirow[t]{2}{*}{ SNO } & \multirow[t]{2}{*}{ Variables } & & \multirow{2}{*}{$\begin{array}{l}\text { Case in } \\
\%\end{array}$} & \multirow{2}{*}{$\begin{array}{l}\text { control in } \\
\%\end{array}$} & \multicolumn{2}{|l|}{$95 \% \mathrm{Cl}$} & \multirow[t]{2}{*}{ COR } & \multirow{2}{*}{$\begin{array}{l}\mathrm{P} \text { - } \\
\text { value }\end{array}$} \\
\hline & & & & & Lower & Upper & & \\
\hline \multirow[t]{3}{*}{1} & \multirow[t]{3}{*}{ Age group } & $<5$ years & $5(6 \%)$ & $18(12 \%)$ & 1 & 1 & 1 & 1 \\
\hline & & $5-14 y$ & $17(23 \%)$ & $37(25 \%)$ & 0.192 & 1.9 & 0.605 & 0.389 \\
\hline & & $>15$ & $53(71 \%)$ & $95(63 \%)$ & 0.18 & 1.417 & 0.498 & 0.191 \\
\hline \multirow[t]{5}{*}{2} & \multirow[t]{5}{*}{ Occupation } & Employee & $2(2.7 \%)$ & $23(15 \%)$ & 1.024 & 20.656 & 4.600 & 0.046 \\
\hline & & unemployed & $5(6.7 \%)$ & $8(5.3 \%)$ & 0.195 & 2.104 & 0.640 & 0.462 \\
\hline & & Student & $31(41 \%)$ & $38(25 \%)$ & 0.262 & 0.918 & 0.490 & 0.026 \\
\hline & & Pastoralist & $5(7 \%)$ & $1(0.7 \%)$ & 0.009 & 0.712 & 0.080 & 0.024 \\
\hline & & Farmer & $33(44 \%)$ & $80(54 \%)$ & 1 & 1 & 1 & 1 \\
\hline \multirow[t]{6}{*}{3} & \multirow[t]{6}{*}{ Education } & Ilitrate & $10(13 \%)$ & $21(14 \%)$ & 1 & 1 & 1 & 1 \\
\hline & & Primary & $31(41 \%)$ & $58(39 \%)$ & 0.373 & 2.127 & 0.891 & 0.795 \\
\hline & & Secondary & $17(23 \%)$ & $22(15 \%)$ & 0.23 & 1.648 & 0.616 & 0.335 \\
\hline & & Teritiary & $4(5 \%)$ & $11(7 \%)$ & 0.333 & 5.153 & 1.31 & 0.7 \\
\hline & & Non formal & $8(11 \%)$ & $21(14 \%)$ & 0.412 & 3.79 & 1.25 & 0.693 \\
\hline & & NA & $5(7 \%)$ & $17(11 \%)$ & 0.464 & 5.648 & 1.619 & 0.45 \\
\hline
\end{tabular}


Table 5

; Risk factors Bi-varate Analysis of Bolosso Sore Wereda, SNNPR, 2019

\begin{tabular}{|c|c|c|c|c|c|c|c|c|}
\hline \multirow[t]{2}{*}{1} & \multirow[t]{2}{*}{ Travel History } & Yes & $5(7 \%)$ & 0 & 0 & 0 & 0 & 0.999 \\
\hline & & No & $70(93 \%)$ & $150(100 \%)$ & 1 & 1 & 1 & 1 \\
\hline \multirow[t]{2}{*}{2} & \multirow[t]{2}{*}{ Staying overnight } & yes & $32(43 \%)$ & $42(28 \%)$ & 0.293 & 0.933 & 0.523 & 0.028 \\
\hline & & No & $43(57 \%)$ & $108(72 \%)$ & 1 & 1 & 1 & 1 \\
\hline \multirow[t]{2}{*}{3} & \multirow[t]{2}{*}{ Having ITN } & yes & $70(93 \%)$ & $129(86 \%)$ & 0.159 & 1.214 & 0.439 & 0.113 \\
\hline & & No & $5(7 \%)$ & $21(14 \%)$ & 1 & 1 & 1 & 1 \\
\hline \multirow[t]{3}{*}{4} & \multirow[t]{3}{*}{ ITN Usage } & Always & $36(48 \%)$ & $30(20 \%)$ & 1 & 1 & 1 & 1 \\
\hline & & Sometimes & $34(45 \%)$ & $99(66 \%)$ & 1.240 & 4.425 & 2.343 & 0.009 \\
\hline & & Never & $5(7 \%)$ & $21(14 \%)$ & 1.007 & 5.021 & 2.248 & 0.048 \\
\hline \multirow[t]{4}{*}{5} & \multirow[t]{4}{*}{ Number of ITN } & One & $6(8 \%)$ & $57(38 \%)$ & 0.788 & 9.354 & 2.714 & 0.114 \\
\hline & & $2-3$ ITN & $53(71 \%)$ & $70(47 \%)$ & 0.142 & 1.000 & 0.377 & 0.050 \\
\hline & & 4-6 ITN & $10(13 \%)$ & $2(1 \%)$ & 0.010 & 0.335 & 0.057 & 0.002 \\
\hline & & Non have & $6(8 \%)$ & $21(14 \%)$ & 0.164 & 1 & 1 & 1 \\
\hline \multirow[t]{2}{*}{6} & \multirow[t]{2}{*}{ IRS } & Yes & $35(47 \%)$ & $28(19 \%)$ & 0.242 & 0.844 & 0.452 & 0.013 \\
\hline & & No & $40(53 \%)$ & $122(81 \%)$ & 1 & 1 & 1 & 1 \\
\hline \multirow[t]{2}{*}{7} & \multirow[t]{2}{*}{ Open deep wel } & Yes & $39(52 \%)$ & $57(38 \%)$ & 1.009 & 3.095 & 1.768 & 0.046 \\
\hline & & No & $36(48 \%)$ & $93(62 \%)$ & 1 & 1 & 1 & 1 \\
\hline \multirow[t]{2}{*}{8} & \multirow[t]{2}{*}{ Broken glass } & Yes & $36(48 \%)$ & $43(29 \%)$ & 0.245 & 0.774 & 0.435 & 0.005 \\
\hline & & No & $39(52 \%)$ & 107(71\%) & 1 & 1 & 1 & 1 \\
\hline \multirow[t]{2}{*}{9} & \multirow[t]{2}{*}{ Plastic container } & Yes & $61(81 \%)$ & $59(39 \%)$ & 0.109 & 0.411 & 0.212 & 0.00 \\
\hline & & No & $14(19 \%)$ & $91(61 \%)$ & 1 & 1 & 1 & 1 \\
\hline \multirow[t]{2}{*}{10} & \multirow[t]{2}{*}{ Gutter } & Yes & $24(32 \%)$ & $42(28 \%)$ & 0.453 & 1.509 & 0.826 & 0.535 \\
\hline & & No & $51(78 \%)$ & $108(72 \%)$ & 1 & 1 & 1 & 1 \\
\hline \multirow[t]{2}{*}{11} & \multirow[t]{2}{*}{ Stagnant water } & Yes & $58(77 \%)$ & $88(59 \%)$ & 0.221 & 0.782 & 0.416 & 0.006 \\
\hline & & No & $17(23 \%)$ & $62(41 \%)$ & 1 & 1 & 1 & 1 \\
\hline \multirow[t]{2}{*}{12} & \multirow[t]{2}{*}{ Intermittent River } & Yes & $41(55 \%)$ & $61(41 \%)$ & 1.032 & 3.162 & 1.806 & 0.038 \\
\hline & & No & $34(45 \%)$ & $89(59 \%)$ & 1 & 1 & 1 & 1 \\
\hline 13 & Tick grass & Yes & $6(8 \%)$ & $14(9 \%)$ & 0.436 & 3.216 & 1.184 & 0.741 \\
\hline
\end{tabular}


Page $11 / 19$ 
Table 6

; Multivariate analysis of risk factors for malaria outbreak Bolosso Sore wereda, Wolayta zone, SNNPR, Ethiopia, 2019

\begin{tabular}{|c|c|c|c|c|c|c|c|c|}
\hline \multirow[t]{2}{*}{ SNO } & \multirow[t]{2}{*}{ Variables } & \multirow[t]{2}{*}{ Category } & \multirow[b]{2}{*}{$\begin{array}{l}\text { Case in } \\
\%\end{array}$} & \multirow[b]{2}{*}{$\begin{array}{l}\text { Control } \\
\text { in \% }\end{array}$} & \multirow[t]{2}{*}{ AOR } & \multicolumn{2}{|l|}{$95 \mathrm{Cl}$} & \multirow{2}{*}{$\begin{array}{l}\text { P- } \\
\text { Value }\end{array}$} \\
\hline & & & & & & Lower & Upper & \\
\hline \multirow[t]{5}{*}{1} & \multirow[t]{5}{*}{ Occupation } & Employee & $2(2.7 \%)$ & $23(15 \%)$ & 1.832 & 0.318 & 10.537 & 0.498 \\
\hline & & unemployed & $5(6.7 \%)$ & $8(5.3 \%)$ & 0.079 & 0.013 & 0.501 & 0.007 \\
\hline & & Student & $31(41 \%)$ & $38(25 \%)$ & 0.187 & 0.070 & 0.515 & 0.001 \\
\hline & & Pastoralist & $5(7 \%)$ & $1(0.7 \%)$ & 0.027 & 0.001 & 0.535 & 0.018 \\
\hline & & Farmer & $33(44 \%)$ & $80(54 \%)$ & 1 & 1 & 1 & 1 \\
\hline \multirow[t]{2}{*}{2} & \multirow{2}{*}{$\begin{array}{l}\text { Staying } \\
\text { overnight }\end{array}$} & yes & $32(43 \%)$ & $42(28 \%)$ & 0.372 & 0.149 & 0.930 & 0.034 \\
\hline & & No & $43(57 \%)$ & 108(72) & 1 & 1 & 1 & 1 \\
\hline \multirow[t]{3}{*}{3} & \multirow[t]{3}{*}{ ITN Usage } & Never & $36(48 \%)$ & $30(20 \%)$ & 32.098 & 3.570 & 288.633 & 0.002 \\
\hline & & Sometimes & $34(45 \%)$ & $99(66 \%)$ & 10.214 & 1.163 & 89.725 & 0.036 \\
\hline & & Always & $5(7 \%)$ & $21(14 \%)$ & 1 & 1 & 1 & 1 \\
\hline \multirow[t]{4}{*}{4} & \multirow{4}{*}{$\begin{array}{l}\text { Number of } \\
\text { ITN }\end{array}$} & One & $6(8 \%)$ & $57(38 \%)$ & 0.112 & 0.010 & 1.217 & 0.072 \\
\hline & & $2-3$ ITN & $53(71 \%)$ & $70(47 \%)$ & 0.014 & 0.001 & 0.145 & 0.000 \\
\hline & & $4-6$ ITN & $10(13 \%)$ & $2(1 \%)$ & 0.002 & 0.000 & 0.044 & 0.000 \\
\hline & & Non have & $6(8 \%)$ & $21(14 \%)$ & 1 & 1 & 1 & 1 \\
\hline \multirow[t]{2}{*}{5} & \multirow[t]{2}{*}{ IRS } & Yes & $35(47 \%)$ & $28(19 \%)$ & 0.149 & 0.056 & 0.396 & 0.000 \\
\hline & & No & $40(53 \%)$ & 122(81) & 1 & 1 & 1 & 1 \\
\hline \multirow[t]{2}{*}{6} & \multirow{2}{*}{$\begin{array}{l}\text { Open deep } \\
\text { well }\end{array}$} & Yes & $39(52 \%)$ & $57(38 \%)$ & 0.423 & 0.173 & 1.033 & 0.059 \\
\hline & & No & $36(48 \%)$ & $93(62 \%)$ & 1 & 1 & 1 & 1 \\
\hline \multirow[t]{2}{*}{7} & \multirow[t]{2}{*}{ Broken glass } & Yes & $36(48 \%)$ & $43(29 \%)$ & 0.193 & 0.074 & 0.506 & 0.001 \\
\hline & & No & $39(52 \%)$ & 107(71) & 1 & 1 & 1 & 1 \\
\hline \multirow[t]{2}{*}{8} & \multirow{2}{*}{$\begin{array}{l}\text { Plastic } \\
\text { container }\end{array}$} & Yes & $61(81 \%)$ & $59(39 \%)$ & 0.134 & 0.050 & 0.361 & 0.000 \\
\hline & & No & 14(19\%) & $91(61 \%)$ & 1 & 1 & 1 & 1 \\
\hline \multirow[t]{2}{*}{9} & \multirow{2}{*}{$\begin{array}{l}\text { Intermittent } \\
\text { river }\end{array}$} & Yes & $41(55 \%)$ & $61(41 \%)$ & 0.166 & 0.065 & 0.425 & 0.000 \\
\hline & & No & $34(45 \%)$ & $89(59 \%)$ & 1 & 1 & 1 & 1 \\
\hline
\end{tabular}


In addition to the above analysis in the study area not only in the study area in the whole country there were no repellents and there were no screening of houses for malaria.

\section{Environmental Assessment}

Observation was conducted for availability of stagnant water, building for fish breeding, broken glass, intermittent river near to the community and other potential mosquito breeding sites. In all assessed kebeles, it was identified that there was larvae of mosquitoes in observed stagnant water by naked eye.

\section{Public health intervention}

A Total of 10 kebeles were sprayed with profoxer chemical. Communities were mobilized and taught on prevention and control measures of malaria disease. Active case search and early management were done at community and health facility level. Larvicide was done those had stagnant water and larvae were seen by Abet chemical.

\section{Discussion}

In our study area male Populations were more affected (51\%) than female (49\%). this is might be due to the fact that males are usually engaged in outdoor activities such as protecting domestic animals and agriculture activities. This study was similar to Arbaminch zuria woreda, Gamogofa zone SNNPR (54.63\%) [7] which is lower than Arbamich Zuria wereda. But higher than the Indian malaria outbreak investigation, $50.6 \%$ of the malaria cases were males [8].

Age group of 15 years and greater than 15 years were more affected with AR of 72 per 100 populations than other age group. Similar studies were done in Zimbabuwe (50 per 100) and it is higher than that of Zimbabwe [9]. This is might be due to higher ages have lower immunity and the productive ages were in night activities.

This study revealed that, the high proportion of Plasmodium falciparum (75\%) and p.vivax (25\%) cases shows difference as compared to the nationally registered proportion of Plasmodium falciparum and plasmodium Vivax which is $60 \%$ and $40 \%$ respectively [10]. Most of studies done on malaria were similar to our study. During malaria epidemics, the dominance of p. falciparum over the other species is common in Ethiopia. This finding also disagrees the study conducted in Bena Tsemay district in SNNPR to assess prevalence and risk factors of malaria where proportion of p. falciparum accounted 64.3\% [11]. The possible reason for this high case positive rate of this outbreak maybe linked to high sensitivity of the Malaria rapid diagnostic test.

The national malaria prevention and control strategy recommends application of IRS as at least once in a year with $100 \%$ coverage, and at least one ITN per two people in malaria high-risk areas [12]. Despite this fact, IRS was not applied prior to the outbreak rather on risky area applied who had stagnant water around their home and early replacement of ITNs was not done. This might be related to poor planning and /or implementation of malaria prevention and control strategies. Households who had been using 
the ITNs other than its intended purpose were also observed. This could be due to poor monitoring of the communities after distributing the ITNs. In our study area households have 2-3 bed net and 4- 6 bed nets (OR 0.377, 95\% Cl; 0.142-1.000 and OR $0.05795 \% \mathrm{Cl}$; 0.010-0.335 respectively) less likely to be affected by malaria infection than those who have one and no have bed nets. This may be due to lack of enough bed nets for those who have many family members as recommended [12].

presence of intermittent rivers nearest to the community, OR 1.806 (95\% $\mathrm{Cl} ; 1.032-3.162)$ and open deep well OR $1.768(95 \% \mathrm{Cl} ; 1.009-3.095)$ were independent risk factors for onset of the outbreak of malaria. A similar study done in Northwest Ethiopia, Smada District, Amhara region OR 5.41 (95\% Cl; 2.11-10.00) and our study is lower than that of Asgede Tsimbla district and the above one. This independent risk factor was due to the fact that following high rainy season there will be flooding as a result, in lowland areas the water stays as stagnant water facilitating mosquito breeding result in malaria infection [13].

The odds of developing malaria among people who used ITN sometimes and never use ITN was nearly 32 and 10 times (AOR; 32.098; 95\%Cl: 3.570-288.633 and AOR 10.214; 1.163-89.725 respectively) compared to who use ITNs frequently. Similar finding was also reported from study in India [14] and it is higher than that of India. This might be due to lack of knowledge about the use of ITN. Having poor knowledge related to malaria prevention and transmission, stagnant water and tick grass had no association with malaria illness in multivariate analysis $(\mathrm{OR}=0.83 ; 95 \% \mathrm{Cl} ; 0.401-1.716)$. Similar study is done in Dasenech wereda in South Ommo in SNNPR [15].

As a limitation two HCs were not included in the study because of their topography difficulty and the number of cases somehow small.

\section{Conclusion And Recommendation}

In conclusion there were malaria outbreak in Bolosso Sore wereda over two months starting from the mid of 17th Epi Week to 28th epi. week. Presence of intermittent rivers nearest to the community, open deep well near to their home and usage of ITN (those ITN use sometimes and never use ITN) were independent risk factors for onset/occurrence of the outbreak of malaria. And IRS, tick grass, staying overnight, number of ITN those given to the community or poor accesses, broken glass and plastic container were less risk factor for the infection of malaria than their counterparts or preventive factors for malaria infection. And also, there were no malaria repellents all over the wereda. And the malaria patients or risky kebeleas of their homes were not screened.

Therefore, malarias areas of the wereda insecticide treated bed net should be distributed for all households according to their family member. Beside this, utilization of bed net should be monitored and optimized. Regular indoor residual spray per required standard should kept in place. Identification and removal of potential mosquito breeding sites should be conducted by maximizing community participation. And during the outbreak they should be use line list format that is used for response. 


\section{Declarations}

\section{Ethical Consideration}

All participants were informed about the objective of the study, confidentiality of the participant was assured and informed consent was sought from and given by the participants, with the knowledge they were free to withdraw at any time. Ethical clearance was obtained from the institutional review board of Ethiopian public health institute and the support letter was written from Welayta zone health bureau to Bolosso sore wereda health office.

\section{Consent for Publication}

Not applicable

\section{Availability of Data and Materials}

The dataset is available on from Mr. Awol Dawud of the corresponding author.

\section{Competing Interests}

We have declared that we have no competing interests.

\section{Funding}

We have no any means of funding of this research.

\section{Authors' Contributions}

$A D$ designed the study, participated in the training and data collection, performed analysis, interpretation of data, drafted the paper and prepared the manuscript. HH and ZA assisted in the design, participated in data analysis and comment the drafts of the manuscript. All authors read and approved the final manuscript.

\section{Acknowledgements}

We would like to thanks our advisors, for their guidance and constructive comments during our work. Our heartfelt gratitude goes to the Saint Paul's Hospital Millennium medical College for giving us this opportunity and funding for this research. In addition, we would like to thank SPHMMC psychiatry department staff for their constructive advice, guidance and help. In general, our sincere gratitude also goes to all supervisors, data collectors and study participants. 


\section{References}

1. Daddi J, AAea. Analysis of malaria surveillance data, Biomed central, 2012:1-14.

2. FMOH, World malaria day, 25 April 2011.

3. Draft Guideline for malaria vector control in Ethiopia; Malaria and Other Vector-borne Diseases Prevention and Control Team; Diseases Prevention and Control Department; Federal Ministry of Health, Addis Ababa, Ethiopia, January 2002.

4. Epidemiology and Ecology of Disease and Health in Ethiopia, Third Edition, Edited by:Yemane Berhane; Damen Haile Mariam; Helmut Kloos, Ethiopia, 2011.

5. Addisu Workineh Kassa MAT, and Addisu Gize Yeshanew. Assessment of Control Measures and Trends of Malaria in Burie-Zuria District, West Gojjam Zone, Amhara Region. Hindawi: North West Ethiopia; 2015. pp. 1-5.

6. Gemechu Shume Bejiga. Malaria Outbreak Investigation and Intervention in Ilu woreda. Ethiopia: South-Western Oromiya; 2013.

7. World malaria report 2018. World Health Organization 2018, ISBN 978-92-4-156565-3.

8. Nigatu, Tarekegn. Malaria Outbreak Investigation, Chano-Mile kebele. Arbaminch Zuria Woreda, SNNPR; 2013.

9. Rashmi, Sharma. Epidemiological investigation of malaria outbreak in village Santej, district Gandhi Nagar (Gujarat), Nov, 2006, Indian J. Prev. Soc. Med. Vol. 37 No $3 \& 4$.

10. Tinashe KUREYA, Augustine NDAIMANI, Maxwell MHLANGA, Malaria Outbreak Investigation in Chipinge, Zimbabwe: A Case-control Study, Iran J Parasitol: Vol. 12, No. 3, Jul-Sep 2017, pp.423432.

11. Debo W, Kassa H. Prevalence of malaria and associated factors in Bena Tsemay district of pastoralist community. Southern Ethiopia; 2016.

12. Wondimu MS, Woldesemayat EM, Aselle TA. Malaria Outbreak Investigation in Pastoral Communities of BenaTsemay District, Southern Ethiopia: A Case Control Study. American Journal of Health Research. 2019;7(3):31-7.

13. Baymot Workineh FA, Mekonnen. Mekonnen Sisay and Kedir Abdela Gonete, Malaria outbreak investigation and contracting factors in Simada District, Northwest Ethiopia: a case-control study, Workineh et al. BMC Res Notes. 2019;12:280.

14. Yadav K. Socio-economic determinants for malaria transmission risk in an endemic primary health centre in Assam, India. Infectious Diseases of Poverty. 2014;3:19.

15. Seyoum, Wendafrash. Malaria outbreak investigation and Response in Dasenech District. SNNRP: South Omo zone; 2018.

\section{Figures}




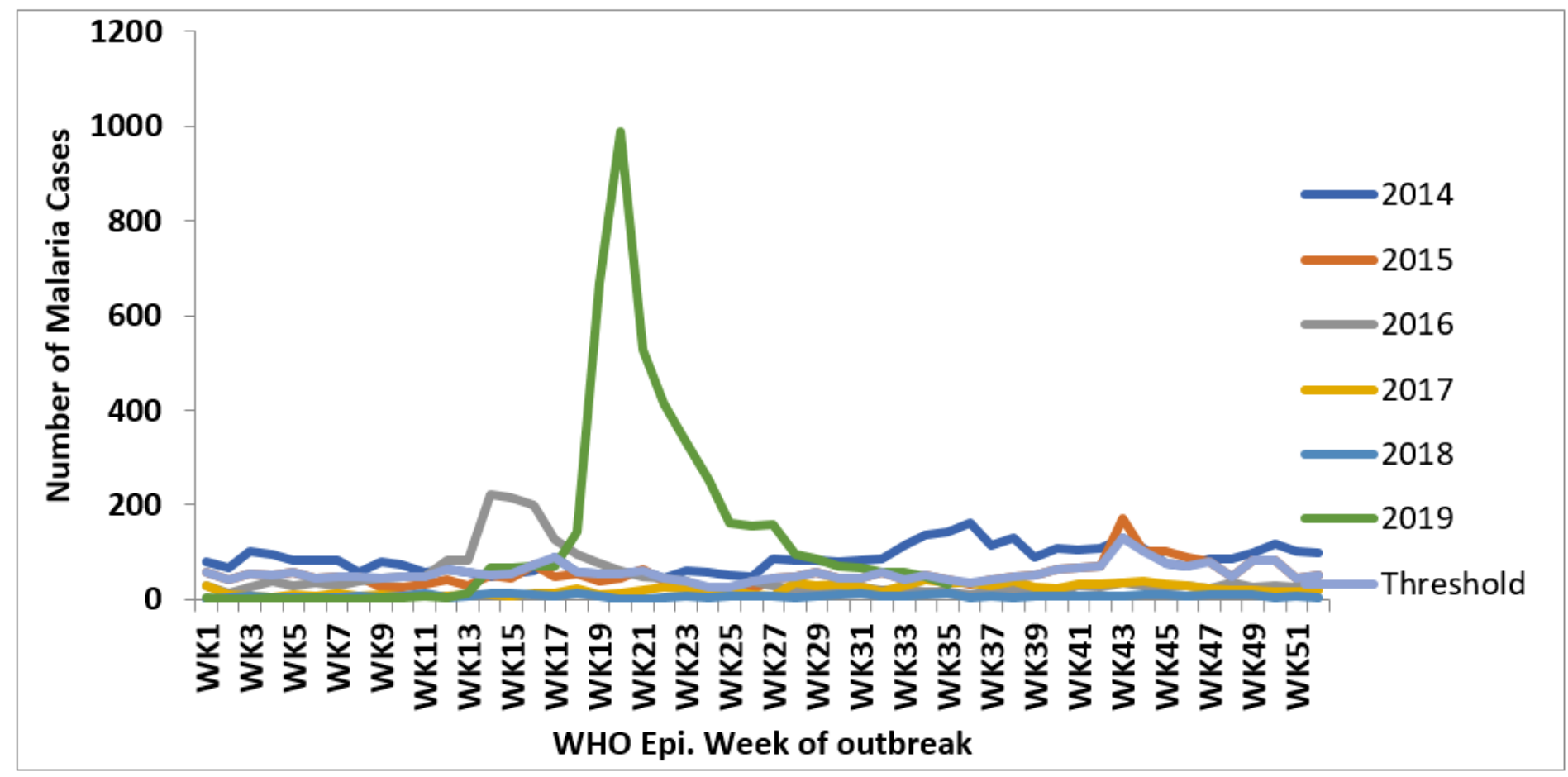

Figure 1

Epidemic threshold of malaria in Bolosso Sore Woreda from 2014



Figure 2 
Epicurve of Bolosso Sore woreda based on PHEM weekly data Wolayta Zone, SNNPR, and Ethiopia September, 2019

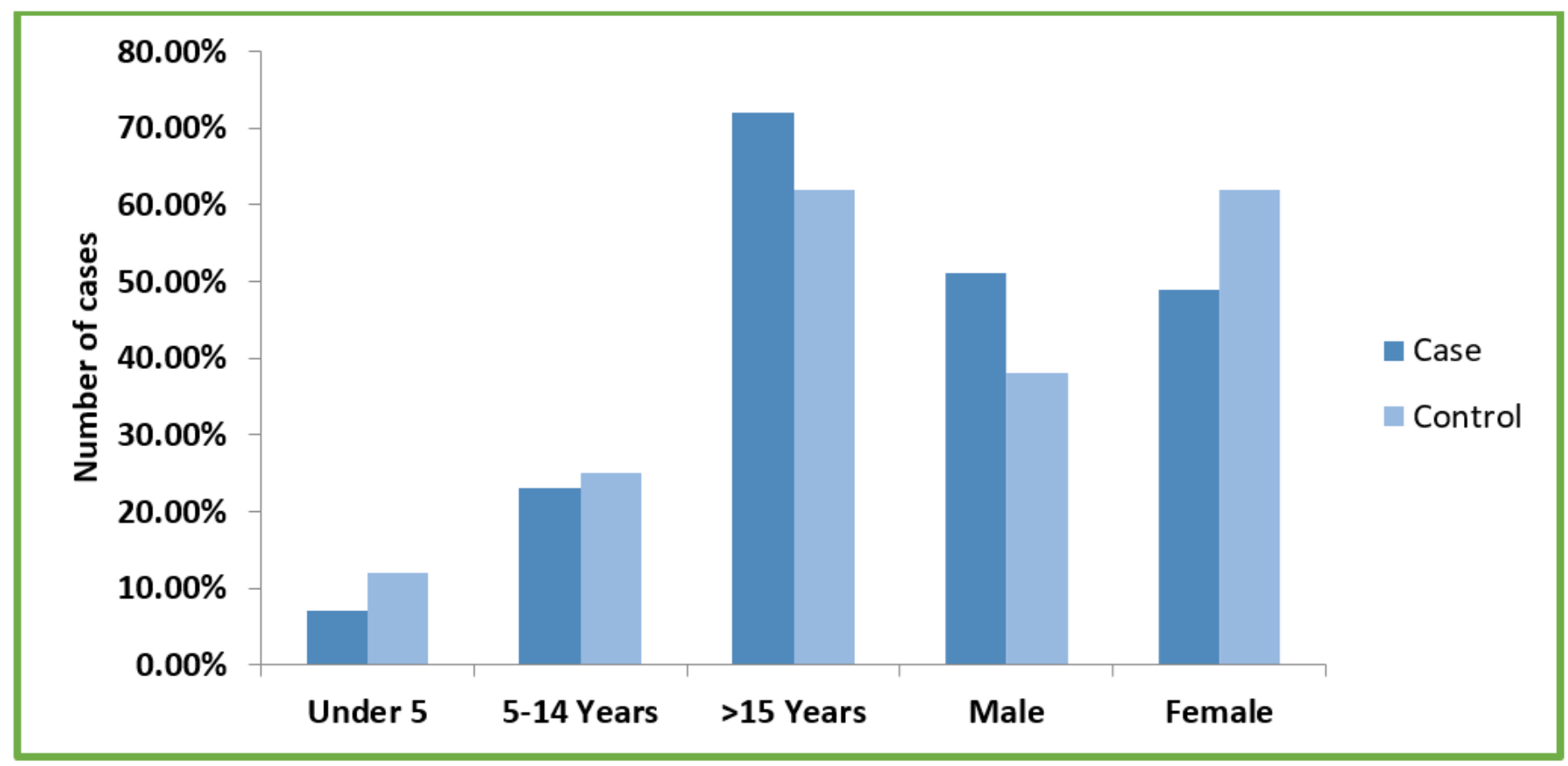

Figure 3

Description of Age and sex of Bolosso Sore wereda, September 2019



Figure 4 
Small Damp or Building for fish breeding in Achura Cluster Tiyo kebele.

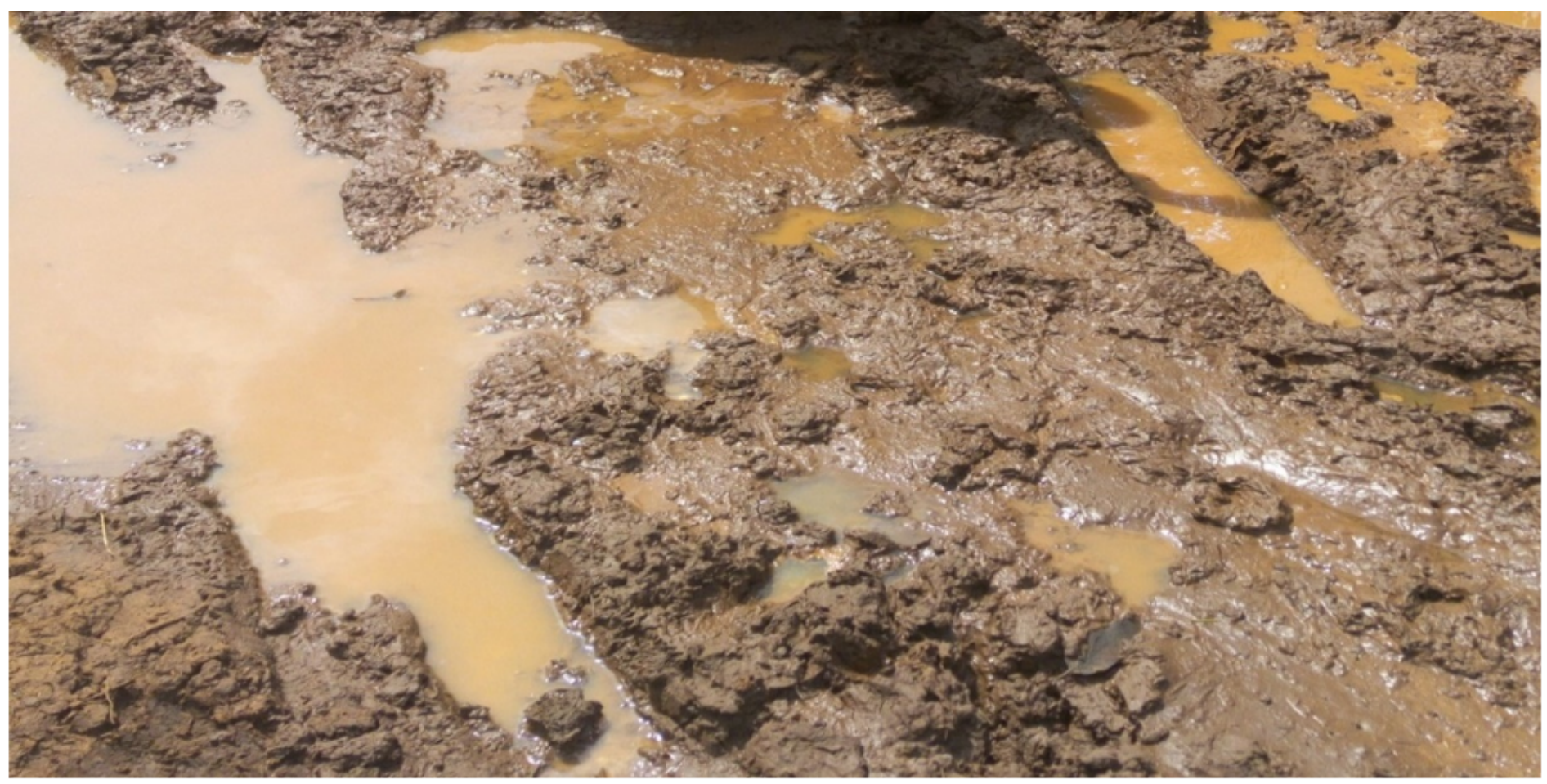

Figure 5

Stagnant water that found in Achura Cluster Tiyo Kebele 